\title{
Knowledge, perceptions and attitudes of final year Medical, Occupational Therapy and Sport Science students regarding Physiotherapy, in KwaZulu Natal.
}

\begin{abstract}
Knowledge, perceptions and attitudes about physiotherapy has affected its status. In a developing profession whose patient base is still significantly dependent on referral from medical practitioners, certain stereotypic attitudes about it require attention. This study investigated the knowledge, perceptions and attitudes of the 2009 final year medical, occupational therapy and sport science students at one university in KwaZulu Natal, regarding physiotherapy. A saturation sample of 292 students from the selected groups was invited to participate in the study. The cross sectional survey used a questionnaire with open and closed ended questions. The data was reduced to percentages and analysed using Chi square tests at $p<0$, 05. The overall

\begin{tabular}{|c|}
\hline Puckree T, PhD,PT; \\
Harinarain R, B. Physio, \\
Ramdath P, B. Physio, \\
Singh R, B. Physio, \\
Ras J, B. Physio \\
\\
\\
Faculty of Health Sciences, \\
Durban University of Technology and \\
Department of Physiotherapy, \\
University of KwaZulu Natal. \\
\hline
\end{tabular}
response rate was $51 \%$ with $95 \%$ occupational therapy, $71 \%$ sport science and only $31 \%$ medical students responding. About $74 \%$ of the respondents had adequate knowledge about physiotherapy. Seventy five percent of medical and 50\% of OT students knew that physiotherapists were first contact practitioners. Over $50 \%$ of the respondents who had experienced physiotherapy displayed positive attitudes and felt that physiotherapy was a good career choice. Massage was the best known (95\%) and electrotherapy the least known (44\%) modality. Orthopedics (88\%), sports physiotherapy (84\%) and rehabilitation (78\%) were better known. We conclude that the response rate to the study especially by medical students is of concern despite the overall positive attitudes displayed by the participants.
\end{abstract}

KEY WORDS: KNOWLEDGE, ATTITUDES, PERCEPTIONS, PHYSIOTHERAPY, HEALTH SCIENCE STUDENTS.

\section{INTRODUCTION}

The recognition of a profession is dependent on the knowledge, attitudes, and perceptions of the public and stakeholders (Dalley and Sim 2001). Generally these attributes are developed based on exposure to practices by the professionals. Despite the growth in the evidence base, scope of practice through research and a real demand for services, physiotherapy is still struggling to achieve status and be recognized as an essential service within health care. This is reflected in the remuneration package for public sector physiotherapists in South Africa (South African Society of Physiotherapy 2009).

Medical and health care professionals and the public have inaccurate perceptions based on inadequate knowledge which affect their attitudes towards physiotherapy (Harris 1992). Kenny and Adamson (1993) found that physio- therapists are aware that doctors do not have an adequate knowledge and understanding of physiotherapy. Harris (1992), almost two decades ago reported that some patients have shown dissatisfaction with medical practitioner's lack of knowledge of physiotherapy services and the availability of alternative services. More recent evidence (Holdsworth et al 2008) suggests that general medical practitioners recognize physiotherapists as complement practitioners for the management of musculoskeletal conditions.

If the public and related health care practitioners are ignorant about the role of physiotherapy in health care, recognition and professionalization will continue to be hampered and therapy will be sought from alternate care practitioners. Kallus et al (1999) believe that because the public is not really clear about the services offered by physiotherapists these professionals have sufficient reason to determine what the public and other health care professionals and students truly know about physiotherapy.

Several dated and recent international studies, have examined the knowledge, attitudes and perceptions of physiotherapy by doctors and medical students (Silva et al 1981, Stanton et al 1985, Kenny and Adamson 1992, Lee and Shepard 1998), occupational therapists (Parker and Chan 1986), physiothera-
Corresponding author:
Prof. T. Puckree
Faculty of Health Sciences
Durban University of Technology
PO Box 1334
Durban
4000
Email: puckreet@dut.ac.za 
pists (Miles-Tapping 1992) physical therapy students (Turner 2001), general college students (Prati and Liu 2006), nurses (Dalley and Sim 2001), health science students (Hawk et al 2002, Hind et al 2003), high school learners (Kallus et al 1999, Ogiwara and Nozoe 2005), and the public (Luna-Massey and Smyle 1982, Parker and Chan 1986, Sheppard 1994, Summers 2003). A single study in the South African literature (Naidoo and Buhler 2009) examined the knowledge, attitudes, and perceptions of EThekwini district chiropractor and physiotherapy students about each other's roles.

The South African Society of Physiotherapy markets the profession vigorously and has implemented several strategies to achieve recognition for the profession (South African Society of Physiotherapy 2009). However, only the identification of critical contributory factors will assist in implementing the most effective public relations strategies. Ultimately it is the responsibility of every physiotherapist to show the public that physiotherapists are truly first line practitioners and capable of both making and receiving referrals. The purpose of the present study was to determine the knowledge, attitudes, and perceptions of medical, occupational therapy and sport science students in KwaZulu Natal regarding physiotherapy and identifying the factors that may play a role in improving recognition of the profession.

\section{METHODS}

A cross sectional survey with qualitative and quantitative components was undertaken at one University in EThekwini District in South Africa. Final year health science students specifically medical (228), occupational therapy (12) and sport science (52) students from the 2009 class were invited to participate. Registration lists obtained from each Faculty office allowed exclusion of students' non-resident (South Africa or EThekwini district) or transferring from physiotherapy to any of the chosen professions, to eliminate exposure to physiotherapy as a contaminator. The four page questionnaire with open and closed ended questions (appendix 1) based on the literature (Tsuda et al 1982,
Lee and Sheppard 1998, Webster et al 2008) consisted of three sections namely biographical details, attitudes and perceptions and knowledge. Content and construct validity and internal consis tency of the questionnaire were checked using a pilot study. Third year occupational therapy students and physiotherapy lecturers participated in the pilot study. No changes were required as a result of the pilot study and the researchers were assured that the questionnaire would achieve the objectives of the study.

All participants signed fully informed consent forms after permission to conduct the study was obtained. The Faculty of Health Sciences Ethics Committee approved the study. Due to the clinical placements of the medical and occupational therapy students during data collection, questionnaires with complete instructions and information sheet, were handed to clinical group student representatives to hand to medical and occupational therapy students. Questionnaires were administered to sport science students by the researchers. The questionnaires were collected by the researchers after a week. An e-mail follow up was undertaken to increase the response rate by medical students.

The data from the questionnaires were reduced to percentages and descriptions by theme. The adequate knowledge scores were derived by quantifying responses obtained on work environment, medical fields, referrals received, conditions treated and treatment modalities used by physiotherapists. The attitude score was calculated by obtaining a percentage of actual response to overall past physiotherapy exposure, if the participant would recommend physiotherapy, the rating of the physiotherapist's role in South Africa and the rating of physiotherapy as a career. If the knowledge and attitude scores were $\geq 50 \%$, they were regarded as adequate and positive respectively. The quantitative data were subjected to Chi Square tests and Spearman's Product moment correlations at a probability of $\mathrm{p}<0,05$ using SPSS version 17. The proportion of participants who responded was worked out as a percentage by health science category.

\section{RESULTS}

Of the 292 students approached to participate in the study, only $51.0 \%$ $(n=149)$ responded even after follow up. However only 83, 2\% (124) of the returned questionnaires were eligible for analysis. The analysed questionnaires included 120 in hardcopy and 4 by e-mail. The participants included 71 medical students $(57,3 \%)$, eight occupational therapy $(6,5 \%)$ and 45 sport science students $(36,3 \%)$. Only $31.1 \%$ of the 228 medical students, $66.7 \%$ of the 12 occupational therapy students and $86.5 \%$ of the 52 sport science students returned their questionnaires. Twenty-five respondents $(8.6 \%)$ were excluded, of which seven $(2.4 \%)$ were not South-African citizens, one $(0.3 \%)$ was a dual citizen and seventeen $(5.8 \%)$ did not reside in EThekweni district.

The demographic characteristics of the participants are shown in Table 1. The majority of medical and occupational therapy students were females, while sport science students were mostly male. The majority of the students were between 18-24 years of age. Most of the medical students were African (55\%), occupational therapy students were White $(38 \%)$ and sport science students were Indians (31\%). The race grouped classified as "other" consisted of Coloured students.

All respondents heard about physiotherapy but only 58, 9\% was actually exposed to it through direct treatment by a physiotherapist or a family member or friend being treated.

The majority of respondents (Figure 1) obtained their information about physiotherapy from a family member or relative, a friend or books. The University career day and newspaper were not significant in creating awareness about the profession.

The majority of respondents have adequate knowledge (knowledge score $\geq 50 \%$ ) of physiotherapy (Figure 2). Occupational therapy students were significantly $(\mathrm{p}<0,01)$ more knowledgeable compared to the sport science and medical students.

When respondents were asked about where they thought physiotherapists work, Figure 3 shows that the most 
Table 1: Percentage of respondents by occupational group, gender, age and race.

\begin{tabular}{|c|c|c|c|c|c|}
\hline & & \multicolumn{3}{|c|}{ Occupational Group \% } & \multirow[b]{2}{*}{ Total $\%$} \\
\hline & & Medical & Occupational Therapy & Sport Science & \\
\hline Gender & Male & 42.3 & 0.0 & 66.7 & 48.4 \\
\hline \multirow[t]{2}{*}{ Age } & 18-24 Years & 57.7 & 50.0 & 75.6 & 94.4 \\
\hline & $>25$ Years & 9.9 & 0.0 & 0.0 & 5.6 \\
\hline \multirow[t]{4}{*}{ Race } & African & 54.9 & 25.0 & 28.9 & 43.6 \\
\hline & Indian & 19.7 & 37.5 & 31.1 & 25.0 \\
\hline & White & 5.6 & 37.5 & 24.4 & 14.5 \\
\hline & Other & 19.7 & 0.0 & 15.6 & 16.9 \\
\hline
\end{tabular}

popular areas were identified as public health services, rehabilitation facility, and private practice.

Table 2 shows responses with regard to medical fields in which physiotherapists work. The majority of respondents regardless of occupational group identified orthopedics and sports medicine. None of the occupational therapy respondents thought that physiotherapists work with patients presenting with respiratory disease or thoracic surgery. Fewer medical and sport science students identified obstetrics and gynecology.

More than $80 \%$ of the medical students knew that physiotherapists could receive referrals from biokineticists, chiropractors and medical doctors but not from nursing staff. Only $50 \%$ of the occupational therapy students knew that physiotherapists received referrals from doctors while only $29 \%$ of the sport science students had a similar feeling. About three quarters of medical student respondents and half of occupational therapists knew that patients could self refer to physiotherapists.

As far as conditions treated by physiotherapists, as shown in Table 3, all occupational therapy students were aware that physiotherapists managed a range of conditions compared to medical students and sport science students. Muscle strain, stroke arthritis and para/ quadriplegia were commonly identified.

For treatment modalities used by physiotherapists (Table 4), 100\% of occupational therapy and sport science students and $90 \%$ of medical students chose massage. Other techniques that were popular included manipulation/ mobilization of joints, pre/post operative exercises and cryotherapy. Less than $40 \%$ of medical and sport science students chose electrotherapy.

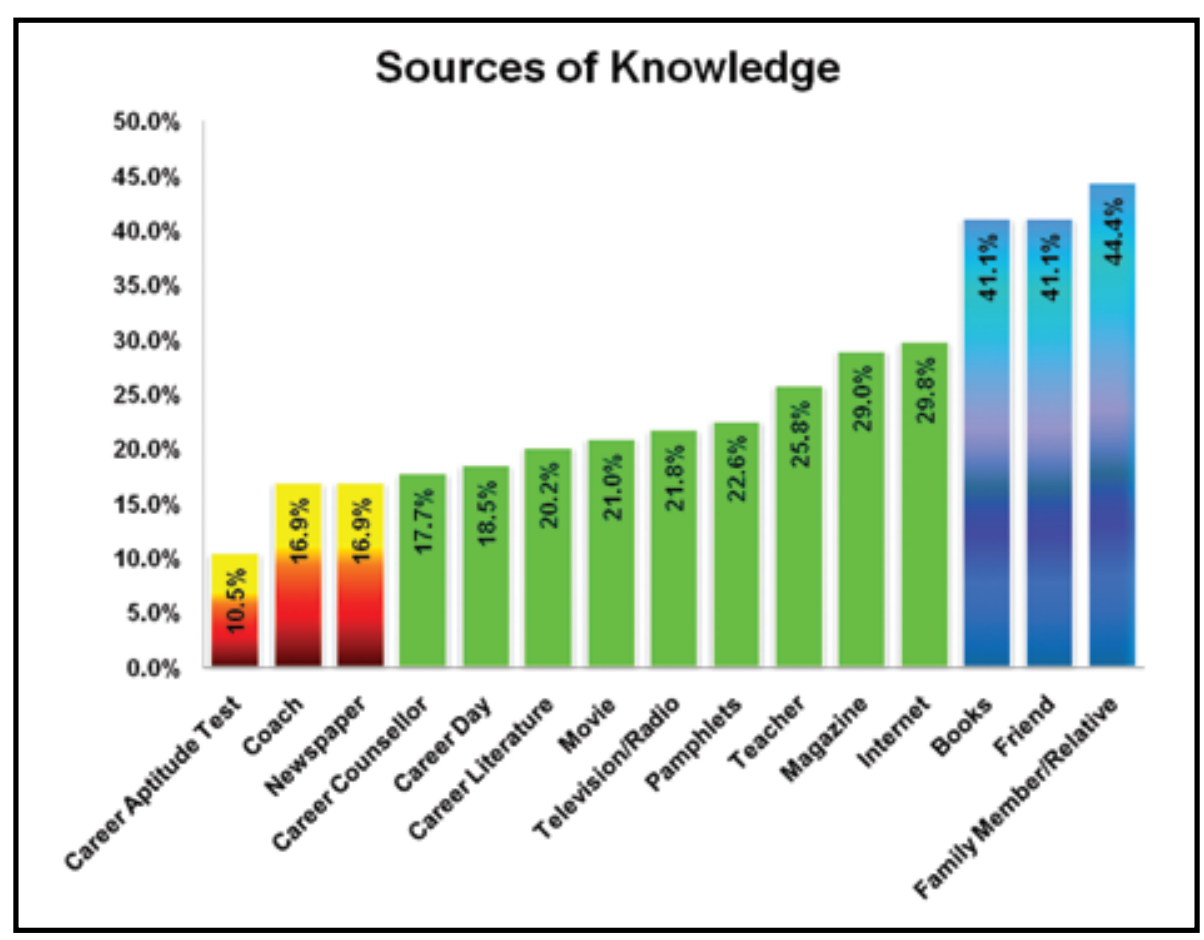

Figure 1: Responses about where participants obtained their information about Physiotherapy

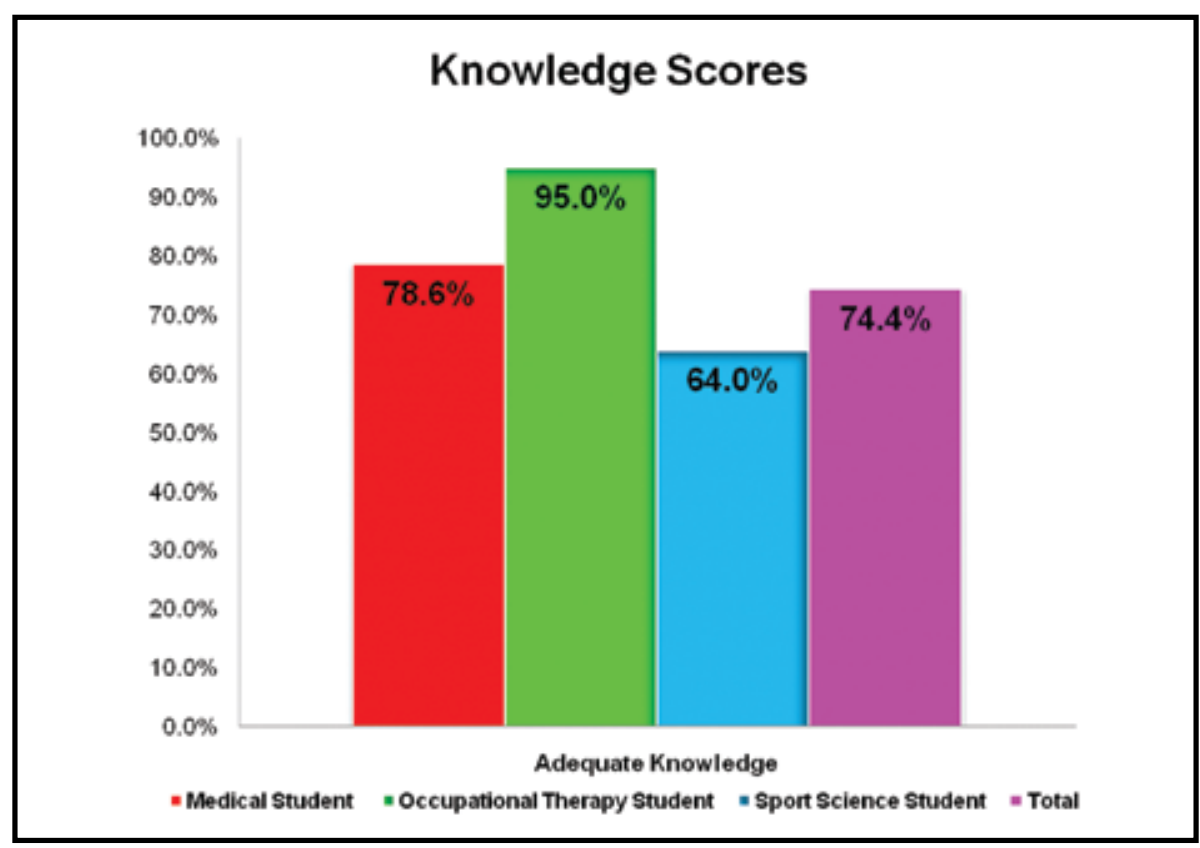

Figure 2: Bar graph showing percentage of respondents by occupational group with adequate knowledge about physiotherapy 
Table 2: Percentage of responses by occupational group for medical fields in which Physiotherapists work.

\begin{tabular}{|c|c|c|c|c|}
\hline \multirow[b]{2}{*}{ Medical Field } & \multicolumn{3}{|c|}{ Occupational Group \% } & \multirow[b]{2}{*}{ Total \% } \\
\hline & Medical & Occupational Therapy & Sport Science & \\
\hline Orthopaedics & 88.7 & 100.0 & 71.1 & 82.3 \\
\hline Sport Medicine & 88.7 & 62.5 & 73.3 & 81.5 \\
\hline Respiratory Disease \& Thoracic Surgery & 83.1 & 0.0 & 28.9 & 64.5 \\
\hline Cardiovascular Disease & 35.2 & 87.5 & 26.7 & 36.3 \\
\hline Obstetrics and Gynaecology & 16.9 & 100.0 & 15.6 & 17.7 \\
\hline Other & 71.5 & 68.8 & 33.3 & 58.9 \\
\hline
\end{tabular}

Table 3: Percentage responses by Occupational Group to conditions treated by Physiotherapists.

\begin{tabular}{|l|l|l|l|l|}
\cline { 2 - 5 } \multicolumn{2}{c|}{} & \multicolumn{2}{l}{ Occupational Group \% } & Sport Science \\
\hline Conditions Treated By A Physiotherapist & Medical & Occupational Therapy & Total \\
\hline Muscle Strain & 87.3 & 100.0 & 95.6 & 91.1 \\
\hline Pre/Post Hemiplegia (Stroke) & 81.7 & 100.0 & 71.1 & 79.0 \\
\hline Arthritis & 76.1 & 100.0 & 80.0 & 79.0 \\
\hline Paraplegia or Quadriplegia & 81.7 & 100.0 & 64.4 & 76.6 \\
\hline Pre/Post Surgery & 74.6 & 100.0 & 71.1 & 75.0 \\
\hline Fractures & 63.4 & 100.0 & 53.3 & 62.1 \\
\hline Brachial Plexus Injuries & 67.6 & 100.0 & 44.4 & 61.3 \\
\hline Head Injuries & 39.4 & 100.0 & 37.8 & 42.7 \\
\hline Wound Care/Pressure Sores & 35.2 & 25.0 & 22.2 & 29.8 \\
\hline Ante-Natal Care & 8.5 & 62.5 & 28.9 & 19.4 \\
\hline Infection & 21.1 & 37.5 & 8.9 & 17.7 \\
\hline AIDS/HIV & 8.5 & 75.0 & 2.2 & 10.5 \\
\hline Other & 46.3 & 69.6 & 29.2 & 40.8 \\
\hline
\end{tabular}

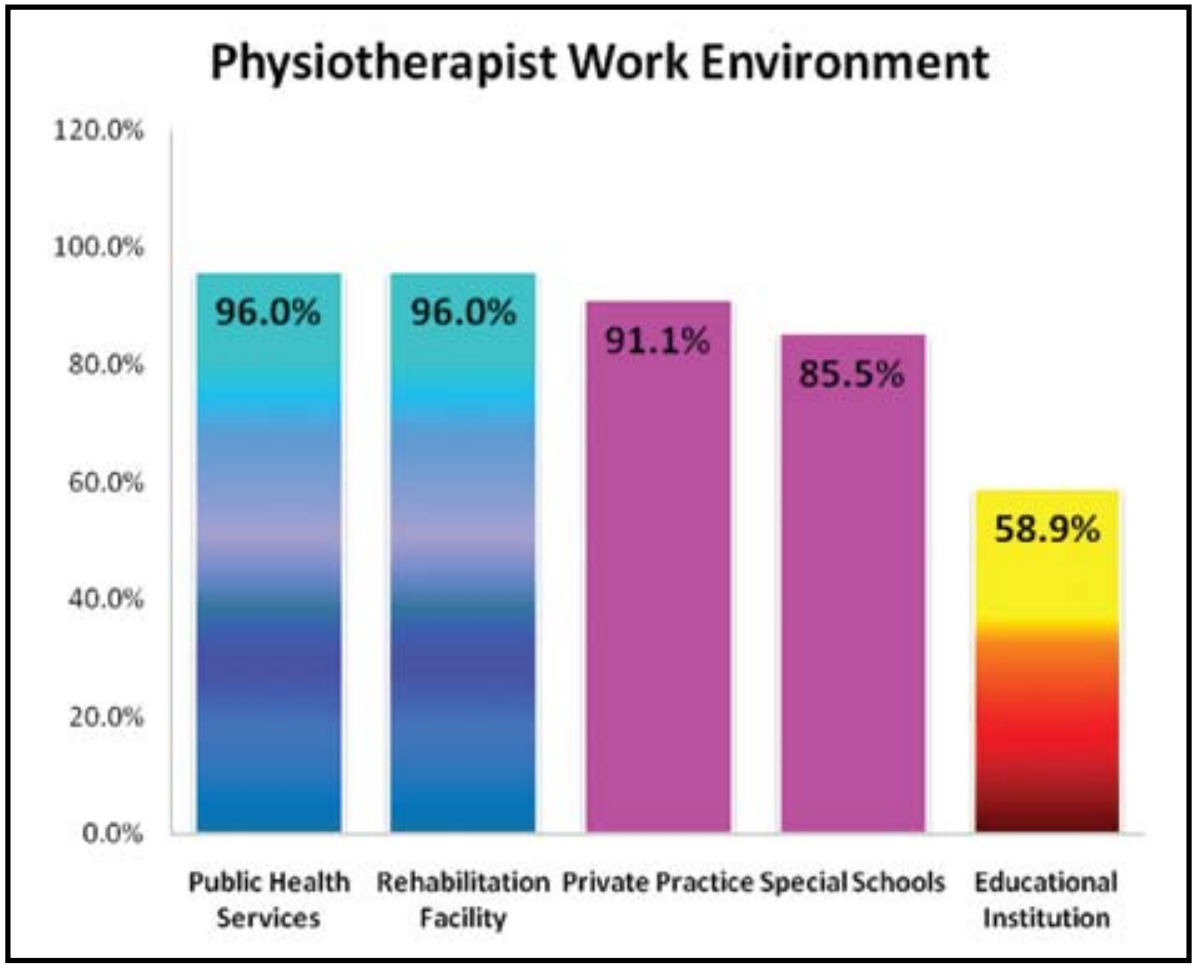

Figure 3: Overall responses (\%) regarding knowledge about physiotherapis work environments by respondents who had heard of physiotherapy previously.
Perceptions and attitudes were determined based on whether the respondents were exposed or not to physiotherapy in the past (Table 5). Forty nine percent of medical students had past exposure compared to 75 and $71 \%$ of occupational therapy and sport science students respectively. This exposure was through themselves, friends or family requiring physiotherapy services.

Past exposure to physiotherapy was significantly correlated $\mathrm{p}<0,05)$ with a positive attitude to physiotherapy in all three groups of respondents. More occupational therapy students who were not exposed to physiotherapy displayed positive attitudes to physiotherapy compared to their colleagues who had exposure. Sixty-eight and $81 \%$ of medical and sport science students reported being positive about the quality of physiotherapy.

More than $80 \%$ of all students would recommend physiotherapy where 
Table 4: Percentage response by Occupational group to modalities used by Physiotherapists.

\begin{tabular}{|l|l|l|l|l|}
\hline Treatment Modalities Used By Physiotherapists & Medical & $\begin{array}{l}\text { Occupational } \\
\text { Therapy }\end{array}$ & $\begin{array}{l}\text { Sport } \\
\text { Science }\end{array}$ \\
\hline Massage & 90.1 & 100.0 & 100.0 \\
\hline Manipulation/Mobilisation of Joints & 88.7 & 100.0 & 86.4 \\
\hline Pre-/Post-Operative Exercises & 83.1 & 100.0 & 88.7 \\
\hline Cryotherapy (Heat/Cold) & 62.0 & 100.0 & 77.8 & 73.3 \\
\hline Electrical Therapy (e.g. Ultrasound) & 31.0 & 37.5 & 68.3 \\
\hline Inhalation Therapy (e.g. Nebulize) & 46.5 & 50.0 & 68.9 & 33.3 \\
\hline Suction and Bagging & 32.4 & 62.5 & 41.9 \\
\hline Other & 65.9 & 71.5 & 31.1 & 64.4 \\
\hline
\end{tabular}

Table 5: Attitude to physiotherapy by occupational group and previous exposure to Physiotherapy.

\begin{tabular}{|c|c|c|c|c|c|}
\hline \multirow{2}{*}{$\begin{array}{l}\text { Past Physiotherapy } \\
\text { Exposure }\end{array}$} & \multirow{2}{*}{ Total Attitude Score } & \multicolumn{3}{|c|}{ Occupational Group \% } & \multirow[b]{2}{*}{ Total \% } \\
\hline & & Medical & $\begin{array}{l}\text { Occupational } \\
\text { Therapy }\end{array}$ & Sport Science & \\
\hline \multirow[t]{2}{*}{ Yes } & Positive Attitude & 72.1 & 66.7 & 81.3 & 75.7 \\
\hline & Ambivalent Attitude & 17.1 & 25.0 & 14.1 & 16.4 \\
\hline \multirow[t]{2}{*}{ No } & Positive Attitude & 56.9 & 75.0 & 65.4 & 59.8 \\
\hline & Ambivalent Attitude & 33.3 & 25.0 & 34.6 & 33.3 \\
\hline
\end{tabular}

required. When asked about their feelings towards physiotherapy as a career, $66 \%, 83 \%$ and $69 \%$ respectively of medical, occupational therapy and sport science students had a positive attitude. The majority of the students, $69 \%$ medical, $83 \%$ occupational therapy and $91 \%$ sport science students perceived that physiotherapists plays an important role in health care in South Africa.

Although several comments were made, the comments that are significant to promote planning interventions to improve the image of the profession are presented below. In the general comments section in which only $21 \%$ of the respondents stated their views about physiotherapy, $8 \%$ was positive and $4,8 \%$ negative. Some of the views are quoted below. Occupational therapy students did not comment.

Sport Science students:

"Physiotherapists play an important role in our sporting industry"

"I think that Physiotherapy is an important asset to the public which is highly under rated similar to Biokinetics and needs to be embraced more by members of the public"

\section{Medical students}

"I realize now that I don't know much about the profession of which I will work so closely within a few years to come.
Please, let us know more about your profession, what exactly you do and how can anyone apply to do the same thing"

"I am actually embarrassed by how much I know about Physiotherapy as a rehabilitation practitioner"

"I find it confusing trying to figure out where physiotherapists fit into the management of most patients"

"Waste of resources"

"Physiotherapy is an unnecessary career; it's a waste of patient's money.... Sorry but this is true".

"In my experience bed ridden patients do not receive physiotherapy."

\section{DISCUSSION}

This study shows an overall adequate knowledge and positive attitudes towards physiotherapy by selected health science students in EThekwini. The overall response rate was acceptable. The poor response by medical students requires further investigation. Some perceptions about physiotherapy were distorted.

Almost ten years ago Lee and Sheppard (1998) suggested that interdisciplinary interaction within the health care team is becoming more recognized as a more effective method of delivering health care. This can only be achieved by team members recognizing and respecting the others professional abilities and technical skills (Whyte and Blackburn 1991, Curran et al 2008). The poor response by final year medical students in this study may reveal an unawareness of the value of interdisciplinary interaction and of physiotherapists in particular. This is reinforced by some of the comments made by some respondents such as "physiotherapy is an unnecessary career".

Levine and Kliebhan (1981) believe that with specific reference to physically handicapped children, no discipline has all the desired diagnostic and treatment services. Our findings of adequate knowledge and positive attitudes by the majority of participants support this. Despite the majority of medical student respondents reporting adequate knowledge and positive attitudes, it must be borne in mind that only $31 \%$ of the medical students participated in this study. It therefore makes sense that patients have shown dissatisfaction with their general medical practitioner's lack of knowledge of physiotherapy and availability of alternative treatments (Harris 1992). Almost 30 years ago, Silva et al (1981) reported that physicians felt that if physiotherapists succeed through education, research and practice, they may be able to work truly 
as colleagues with them. Anecdotally, pockets of physiotherapists in South Africa have achieved this status. It is important for every physiotherapist to assert the quality of their educational degrees and be respected members of the health care team.

Similar to Kallus et al (1999) comments made by respondents in this study suggest that they may have been exposed to physiotherapy but do not understand the specific details of it. Tsuda et al (1982) showed this in their study on high school learners. Although Webster et al (2008) point out that the public and service users are not knowledgeable about physiotherapy, studies like that by Ogiwara and Nozoe (2005) and efforts by professional organizations like the South African Society of physiotherapy show that information is being channeled to the public. From the current study, it is clear that in addition to information, the consumer requires actual hand on experience of what physiotherapy entails (Figure 1).

Similar to our findings Lee and Sheppard (1998) reported that physiotherapists enjoyed a positive reputation amongst Southern Australia medical students. Even Lee and Sheppard (1998) found gaps in the medical students' knowledge regarding conditions treatable by physiotherapists even though their general knowledge was good.

Sources from which individuals obtain their information may influence their knowledge and their perceptions and thereby alter their attitudes to Physiotherapy. In this study although significantly more students had positive attitudes to physiotherapy, more occupational therapy students displayed ambivalent views about the quality of physiotherapy that they were exposed to. Ogiwara and Nozoe (2005) reported that their cohort of study participants failed to identify any sources of information regarding physiotherapy. The current study showed that "word of mouth" through friends and family; direct personal or other exposure and books were the major sources of information. It is interesting to note that few respondents used the University career day or newspapers. In the 19 sources reported by Kallus et al (1999) personal contacts, mass media and career information were significant. Although Kallus et al (1999) reported the media and family members as common sources of information these sources may portray inaccurate information leading to misconceptions. From the comments by medical students in this study, it seems that they received no exposure to physiotherapy, despite the fact that physiotherapy students obtain clinical training alongside medical students in selected teaching hospitals. The physiotherapy department offers lectures to second year medical students and physiotherapy is an academic discipline within the same University. Ewan (1987) reported that the lack of opportunities for medicals students to work with allied health care professionals in the clinical setting has contributed to their lack of appreciation of the skills of these professionals. Lee and Sheppard (1998) stated that $44 \%$ of their participants indicated that they did not know enough about physiotherapy to comment in detail on it. Stanton et al (1985) showed that despite physicians' lack of knowledge about physiotherapy they still referred patients to physiotherapy.

In the current study, medical students were happy to refer patients for physiotherapy even though they were not totally knowledgeable about services rendered. In the past, physiotherapists were dependent on doctors for patient referral. Webster et al (2008) reported that doctor respondents in their study referred less than 30 percent of patients for Physiotherapy. Doctors must be well informed about physiotherapy (Lee and Sheppard 1998) for them to make appropriate referrals. Since word of mouth referrals are only second to doctors' referrals to physiotherapy (Sheppard 1994), perception of physiotherapists seems critical in improving referral rates.

Sixty percent of the respondents in the current study knew that patients can self-refer to physiotherapists. Webster et al (2008) found that $88 \%$ of their respondents in the United Kingdom were supportive of being able to refer themselves to Physiotherapy. The responsibility of self-referral can only come when stakeholders have an adequate knowledge, attitude and perception of physiotherapy so that they can make an informed decision (Webster et al 2008).

Perceptions about quality of services can impact on patients seeking physiotherapy (Potter et al 2003). Stanton et al (1985) believe that physiotherapists are responsible for creating awareness about their profession. Lee and Sheppard (1998) found that only 68\% of college students were aware that Physiotherapists are first contact practitioners. Sheppard (1994) suggested that educating the public about physiotherapy could increase client numbers. In the current study, occupational therapy students who were exposed to physiotherapy actually reported less positive attitudes towards it.

Majority of respondents in the current study knew that Physiotherapists work in private practice. Sheppard (1994) found that the physiotherapists most readily distinguished are the ones in private practice.

The present study showed that the majority of respondents knew that physiotherapists managed musculo-skeletal injuries. Sheppard (1994) reported that patients believed that physiotherapists were specialists in muscular treatment especially pain relief, sport injury management, and back care. Holdsworth et al (2008) reported that general practitioners in their study recognized physiotherapists as complement practitioners for the management of musculoskeletal conditions. Similar to this study, Lee and Sheppard's (1998) participants also identified musculo-skeletal disorders and strokes as conditions treatable by physiotherapists. Holdsworth et al (2008) found that general medical practitioners recognize physiotherapists as complement practitioners for the management of musculoskeletal conditions.

Prati et al (2006), similar to the current study, found that certain modalities are typically associated with physiotherapy namely physical exercise, and massage versus electrical treatments. The respondents were generally not aware that physiotherapists also managed antenatal care and womens' conditions similar to that reported by Sheppard (1994). Respondents indicated a lack of awareness of physiotherapy and a need 
for more vigorous marketing (Webster et al 2008).

All respondents in the current study had heard about physiotherapy compared to the $92 \%$ percent of respondents in the Ogiwara and Nozoe (2005) study who stated that the first time that they had heard about physiotherapy was in the survey that they undertook. The respondents in that study were high school learners. Kallus et al (1999) said that the public may be exposed to and be aware of the profession of physiotherapy but may not necessarily understand the details about it. Relevant activities have been undertaken by physiotherapists to convey information to the public including school children (Ogiwara and Nozoe 2005; SASP 2009). The identification of specific areas in which gaps are, will allow for specific marketing strategies in these areas. College students interested in studying physiotherapy in Arkansas were not aware of the doctoral degree in physical therapy (Prati et al 2006).

Respondents in this study failed to identify areas in which physiotherapists work similar to the findings by Whitfield et al (1996) who believe that physiotherapy does not have a clear identity with the result that the public and health care professionals are unable to differentiate physiotherapy from related professions. Lee and Sheppard (1998) reported that their sixth year medical student respondents found that physiotherapists were progressive, professional and competent with an important role in teaching the public self-responsibility in health care.

The favourable attitudes and supportive perceptions of participants in the current study are supported by Silva et al (1981) who found that physicians thought that physiotherapists were highly professional and possess all five of Moore's criteria of professionalism namely motivation and lifelong commitment to their career, established organization, prolonged period of specialized education and training, orientation towards serving clients through competent application of specialized knowledge and skills and autonomy of judgment within the profession. Luna-Massey and Smyle (1982) found that consumers felt that physiotherapists were not as effec- tive in evaluative skills as the physician. This aspect was not considered in the current study.

Several questions arise from the findings of this study and the available literature on the topic. Although respondents in the studies are adequately knowledgeable and have supportive attitudes and perceptions about the profession and its practitioners, the status of the profession has not changed. Marketing and awareness strategies should target a wide range of the population. The current study showed that the majority of the respondents had exposure to physiotherapy either personally, through their family or friends. Physiotherapy associations around the world are now promoting voluntary service to communities. An audit is required to evaluate the extent of involvement, response rate to surveys and knowledge, perceptions and attitudes.

\section{CONCLUSION}

Final year students from selected health care professions have adequate knowledge and positive attitudes and perceptions towards physiotherapy. Of concern is the $50 \%$ of non respondents. Physiotherapists may need to offer more voluntary services to communities in an effort to educate and create awareness. The study was limited by the poor response of medical students. Time and funding constraints limited the population for this study. The generalizability of the findings is confined to the population under study.

\section{REFERENCES}

Curran VR, Sharpe D, Forristall J, Flynn K 2008 attitudes of health sciences students towards interprofessional teamwork and education. Learning in health and social care 7(3):146-156

Dalley J, Sim J 2001 Nurses' perceptions of Physiotherapists as rehabilitation team members. Clinical Rehabilitation 15:380-389

Ewan CE 1987 Attitudes to social issues in medicine: A comparison of first-year medical students with first-year students in non-medical faculties. Medical Education 21:25-31
Harris MF 1992 Management of chronic musculoskeletal conditions in general practice: Self-care and use of community resources $-\mathrm{A}$ report of a qualitative process. General practice evaluation and program work in progress report. Canberra: Australian Government Printing Services ppl. 3-5

Hawk C, Buckwalter K, Byrd L, Cigelman S, Dorfman L, Ferguson K 2002 Health professions student's perceptions of inter-professional relationships. Academic Medicine 77:354-357

Hind M, Norman I, Cooper S, Gill E, Hilton R, Judd P, Jones S 2003 Interprofessional perceptions of health care students. Journal of Interprofessional Care 17:21-34

Holdsworth LK, Webster VS and McFadyen AK 2008 Physiotherapists' and general practitioners' views of self-referral and physiotherapy scope of practice: result from a national trial. Physiotherapy 94:236-243

Kallus K, Noble D, Bezner J and Keely G 1999 An Assessment of High-School Students' Knowledge of Physical Therapy and the Factors That Influence Their Knowledge. Journal of Physical Therapy Education 13:4-11

Kenny D, Adamson B 1992 Medicine and the health professions: issues of dominance, autonomy and authority. Australian Health Review 15: 319-333

Lee K, Sheppard L 1998 An investigation into medical students' knowledge and perception of physiotherapy services. The Australian Journal of Physiotherapy 44:239-244

Levine MS and Kliebhan L 1981 Communication between physician and physical and occupation therapists: a neurodevelopmentally based prescription. Paediatrics 68:208-214

Luna-Massey P and Smyle L 1982 Attitudes of consumers of physical therapy in California toward the professional image of physical therapists. Physical Therapy 62:309

Miles-Tapping C, Rennie GA, Duffy M, Rooke L and Holstein S 1992 Canadian physiotherapists' professional identity: an exploratory survey. Physiotherapy Canada 44:31

Naidoo N, Buhler L 2009 The perceptions, attitudes and knowledge of physiotherapy and chiropractic students regarding each others' professional practice. South African Journal of Physiotherapy 65: $32-38$ 
Ogiwara S and Nozoe M 2005 Knowledge of Physiotherapy: A Study of Ishikawa High School Students. Journal of Physical Therapy Science 17:9-16

Parker H J, Chan F 1986 Stereotyping: Physical and Occupational Therapists Characterize Themselves and Each Other. Physical Therapy 66:668-672

Potter M, Gordon S, Hamer P 2003 The physiotherapy experience in private practice: the patients perspective. Australian Journal of Physiotherapy 49:195-202

Prati V and Liu H 2006 Perceptions of College Students Regarding the Current Physical Therapy Profession and Professional Education Process. The Internet Journal of Allied Health Sciences and Practice 4:1-6

Sheppard L 1994 Public perception of physiotherapy: implications for marketing. Australian Journal of Physiotherapy 40:265-271
Silva DM, Clark SD, Raymond G 1981 California physicians' professional image of physical therapists. Physical Therapy 61:1152-1157

South African Society of Physiotherapy 2009 http://www.physiosa.org.za/?q=pressrelease accessed 3 February 2010

Stanton PE, Fox FK, Frangos KM, Hoover DH, Spilecki GM 1985 Assessment of Resident Physicians' Knowledge of Physical Therapy. Physical Therapy 65:27-30

Summers M 1993 General practitioners and information on local services. Health Issues 35:32-34

Tsuda HC, Kiser BC, Shepard KF 1982 Factors influencing high school students' knowledge of physical therapy. Physical Therapy 62:1157-1164

Turner P 2001 The occupational prestige of physiotherapy: Perceptions of student physiotherapists in Australia. Australian Journal of Physiotherapy 47:191-200
Webster VS, Holdsworth LK, McFadyen AK, Little H 2008 Self-referral, access and physiotherapy: patients' knowledge and attitudes - results of a national trial. Physiotherapy 94:141-149

Whitfield TWA, Allison I, Laing A, Turner P. 1996 Perceptions of the physiotherapy profession, a comparative study. Physiotherapy Theory and Practice 12:39-48

Whyte M, Blackburn J 1991 Health Sciences. Education review. Cited in: Lee K and Sheppard L (1998): An investigation into medical students' knowledge and perception of physiotherapy services. The Australian journal of physiotherapy 44(4):239-244 